\title{
Networks, Hypertext, and Academic Information Services: Some Longer-Range Implications
}

\section{Ross Atkinson}

Because computer network use is increasing so rapidly, we must begin to consider some of the longer-term issues that relate to scholarly information exchange in a networked environment, and the possible future roles of academic information services in that exchange. The growing capacity of the network, combined with the eventual ability to link any textual units with any others, may well have profound effects on scholarly communication and higher education, especially the relationship between readers and writers. Three examples of key responsibilities that may be assumed by academic information services in the online environment are (a) assistance with institutionally based publication, (b) work with authors on the indexing of their publications, and $(c)$ the design of new, network-based document structures.

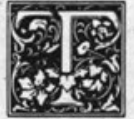

he application of computermediated communication and resource sharing to the creation and exchange of scholarly information has been anticipated for decades, but only recently have librarians begun to witness the kind of rapid increase in the use and utility of networked information that we have for so long been expecting. The use of the network is now expanding so rapidly that the statistics recording that increase are difficult even to comprehend.' In response to the rapidly rising demand for computer networking - not only for scholarly purposes but also in support of government and commercial transactions-Congress has passed the High-Performance Computing Act of 1991, which is intended to "support the establishment of the National Research and Education Network [NREN], portions of which shall, to the extent technically feasible, be capable of transmitting data at one gigabit per second or greater by 1996." Newly introduced legislation, "The Information Infrastructure and Technology Act," would authorize an additional $\$ 1.15$ billion over five years to provide for the effective use of such a vastly expanded national network. ${ }^{3}$ Perhaps the most pressing challenge to those of us responsible for academic information services, therefore, will be to remain somehow conceptually ahead of such developments in order to guide them whenever possible in directions that will ensure the greatest benefits for scholarship and higher education.

We appear to be succeeding in our effort to meet this challenge in the short term-at least to the extent that issues which must be settled before fully effective use of the network for research and 
instruction can be achieved are becoming increasingly well defined. Such shorter-term issues include controversial policy questions, most of which reduce to concerns about who owns or will own which parts of the network, and the extent to which the network should be publicly supported and controlled. ${ }^{4}$ Many of these policy questions derive from the fact that a variety of constituencies will rely increasingly on the network for very different purposes. ${ }^{5}$ Also of immediate concern are legal issues that must be clarified and negotiated, before published information can become broadly available in electronic form. The most important of these for scholarly communication have to do with copyright, and considerable effort is now being devoted to their definition and resolution. ${ }^{6}$ There are also other legal issues relating to privacy and security, although many of these will be of much greater concern to commercial users of the network than to scholarly or academic users. Vaguer and more vexing are the shortterm social and cultural considerations that must be confronted. The most problematic of these from the standpoint of scholarly communication have to do with the willingness of scholars to accept electronic formats as a vehicle of formal publication. ${ }^{8}$ Finally, a variety of shorter-term technical issues that will need to be resolved relate to such issues as network capacity, standards, and protocols. ${ }^{9}$ It is perhaps indicative of the times in which we live that these technical impediments will doubtless be by far the easiest ones to overcome.

Because events and innovations are now finally accelerating so rapidly, however, concentration on the definition and solution of such shorter term issues is not enough. Taking "a 'wait and see' attitude on many key issues," as Richard Katz has recently noted, "is not a viable strategy." ${ }^{\prime 10}$ If academic information services are to exercise some influence over the future direction of scholarly information exchange and higher education, then some thought must also be invested in what appear at the moment to be longerterm issues. (We must designate these as "longer-term" rather than "long-term," not only because such notions are always relative but also because these issues, too, will certainly be upon us much sooner than we expect.) We need to begin to prepare for these developments now; we need to begin to define concepts, to agree upon values, to take positions, if we are to lay the groundwork for decisive action in the future. This preparation will entail, unavoidably, some prediction and speculation about the qualities and uses of the network in its fully developed form. We must be willing, in other words, to undertake a certain amount of conjecture in public about what a network is and what the network will become, if we are to have any chance of influencing its evolution. The consideration of a few of these longer term implications will be the purpose of this paper.

\section{INITIAL DEFINITIONS}

\section{Information Services}

There are clearly many kinds of information, but let us restrict our definition to those groups of (often natural language) signs created by people for purposes of communicating their ideas." The user-scholars, students-locates such sets of signs or information units, therefore, and produces information from them. The primary purpose of information services has always been and will always be to reduce to a minimum the amount of time required by local users to obtain access to that information they need to do their work. ${ }^{12}$ All information service activities are intended ultimately to achieve that single objective. As we move increasingly into an online environment, those service activities will change, but that primary objective will remain the same. Results, in terms of access time reduction, should presumably improve substantially in an online environment. However, information overload-a primary retardant to academic information access since at least the advent of the machine press-will probably also become even more pronounced as more information becomes available online. Efforts to control such overload will no doubt drive the renovation of many information service operations. 
An essential responsibility of information services must be to assist users in determining what information they need to do their work. Without this assistance, the amount of time the user will require to locate such information can be greatly extended. Information service operations provide this assistance by acting upon information-by selecting, distinguishing, referring to, and otherwise privileging individual information units, in order to enhance the user's ability (a) to locate those units and (b) to decide which of those units is worth the time to retrieve and absorb. In the paper environment, this service is provided most clearly through traditional library operations such as collection development, cataloging, and reference. All such services, moreover, regardless of the dominant information format, are necessarily intended to add value to individual information units by differentiating those units from each other in such a way that clientele will be able to make decisions as to the sequence in which they access information. All information exchange is necessarily sequential. Meaning is, in fact, at least partially a product of sequence; to change the sequence, therefore, is always to change the meaning. This is true not only at the sentence (syntactical) level but also at the document level, in the sense that the understanding of an information source is necessarily conditioned at least in part by the reader's (or hearer's) previous knowledge or experience of other sources. A primary purpose of academic information services, therefore, is to assist the student or scholar not only in locating needed information but also in determining which items of information to read (or hear) in which order.

\section{The Network}

John S. Quarterman defines a computer network as "a set of computers communicating by common conventions called protocols over communication media." ${ }^{13} \mathrm{~A}$ useful and concise definition-albeit one that also displays a problem that we encounter frequently in the literature on networks and computers-i.e., reification-the confusion of human and mate- rial relationships. We must assume that it is information which is being communicated, and we have already defined information as consisting of signs. Computers, however, do not exchange signs. They exchange signals, i.e., "units of transmission which can be computed quantitatively irrespective of their possible meaning." ${ }^{14}$ It is these signals that are then later converted into signs, so that users can extract or create information from them. Since communication entails the exchange of signs, it should not be supposed, as Quarterman apparently does, that a computer network consists of "a set of computers communicating." Networks are material transportation devices. At its most basic level, a network is a machine designed to move very small physical objects (packets in the current technology) from one place (or node) to another. It is important, therefore, that we continue to bear the materiality of the network in mind-that we recognize it for the mechanical apparatus it is.

Although there are many computer networks now in existence, these different networks are in some cases very difficult to differentiate. ${ }^{15}$ It is, moreover, the nature and the purpose of networks to be indistinguishable-what we now call "transparent." For our purposes, therefore, it is most convenient to refer, as we have done so far, simply to the network in the generic sense of all of the networks now accessible. We must also note, however, the term computer network is often used to refer to several different concepts. One is clearly the network proper, i.e., the links or highways down which the signals are sent-the transportation system described above. By extension (metonymy), however, the term network is also often used to refer to the content of the databases accessible through the network-so the extended network also includes the information available through (i.e., derivable from) the network proper. Finally, there is what we might call the functional network, that includes the rules or grammar-not only technical (e.g., protocols), but also administrative and legal-which 
regulate the network's operation. ${ }^{16}$ While information services have in the past been concerned primarily with the extended network, it will become increasingly important for academic information services to participate more actively in the direction and operation of the functional network as well.

\section{Hypertext}

The network proper is, in any event, a formal telecommunications instrument designed to connect computers. In considering the future of scholarly information exchange, we must therefore take into account not only the facility of the network but also the effects of computers on scholarly reading and writing. Certainly one of the best approaches to such an assessment is to focus on the phenomenon of hypertext because it is through the concept (if not yet the reality) of hypertext that we begin to sense the most fundamental and far-reaching effects of the computer on communication in general and scholarly information exchange in particular. Hypertext may be viewed both as a symbol and as the most visible manifestation of the radically new capabilities made available by computers. Hypertext also deserves the special attention of librarians because one of its most obvious and frequently described applications will be for bibliographical citation. ${ }^{17}$

A useful current definition of hypertext is provided in a 1988 article describing a hypertext system at Brown University:

In essence, a hypertext system allows authors or groups of authors to link information together, create paths through a body of related material, annotate existing texts, and create notes that direct readers to either bibliographic data or the body of the referenced text. Using a computer-based hypertext system, students and researchers can quickly follow trails of footnotes and related materials without losing their original context; thus, they [students and researchers] are not obliged to search through library stacks to look up referenced books and articles. Explicit connections-links- allow readers to travel from one document to another, effectively automating the process of following references in an encyclopedia. In addition, hypertext systems that support multiple users allow researchers, professors, and students to communicate and collaborate with one another within the context of a body of scholarly material.

Hypermedia is simply an extension of hypertext that incorporates other media in addition to text. With a hypermedia system, authors can create a linked body of material that includes text, static graphics, animated graphics, video, and sound. ${ }^{18}$

The term hypertext was originally coined by Theodor Nelson in $1965 .{ }^{19} \mathrm{He}$ then developed the concept further in other publications, most fully in his now classic Literary Machines. It was in that work especially that Nelson introduced the definition of hypertext as nonsequential writing. ${ }^{20}$ That concept is frequently echoed in other current definitions. ${ }^{21}$ As we noted above, however, sequence is a fundamental component of language, and there can obviously be no such thing as writing or reading "without sequence." What Nelson and others mean, of course, is that hypertext allows the reader to move parts of a document out of their "original" sequence, i.e., to embed them in, or to connect them to, contexts other than those in which the author originally placed them.

To change the sequence is, again, to change the meaning-so that hypertext provides the reader with the power and authority to affect the meaning of the text. We must also recognize, however, that the reader has always had that power anyway. The text consists of signs, and the reader has always brought the meaning to the text by relating the text to previous texts he or she has experienced. Indeed, the potential interrelationship or interconnectedness of all texts has become one of the dominant preoccupations of late twentieth-century philosophy and especially literary theory. In 1966, Julia Kristeva first coined the term intertextuality: "[A]ny text is constructed as a mosaic of quotations; 
any text is the absorption and transformation of another. The notion of intertextuality replaces that of intersubjectivity, and poetic language is read as at least double."22 This concept, as developed especially by Roland Barthes, has become highly influential, and has been applied to a variety of critical purposes..$^{23}$ Care must be taken, as Kristeva noted later, however, not to imagine intertextuality as a linear concept, i.e., "in the banal sense of 'study of sources.'"24 In 1976, Laurent Jenny pointed out that the fundamental metaphors of literary criticism were in fact noticeably shifting from aquatic linear images (e.g., "influences," "sources") to metaphors of webs, fabrics, or networks..$^{25}$ Roland Barthes, in a classic essay on the nature of the text, even noted that the word text itself derives from the Latin texere, which means to weave (cf. "textile"). ${ }^{26}$ The concept of linearity, therefore, has gradually been replaced in the late twentieth century by the realization that understanding is achieved only through a constant rearrangement of a network or matrix of texts. ${ }^{27}$

Hypertext does not engender intertextuality, therefore, but rather merely heightens its utility and effect. More precisely, hypertext permits the easy creation of new syntagmatic contexts, in the sense that it permits any text or group of texts to be reduced to its constituent elements, so that these elements can be rearranged or reconstituted in new sequences. While such a function has many uses, the one that is most frequently noted, as in Nicole Yankelovich's definition above, is for purposes of increasing the application and extent of bibliographic citations (i.e., surrogate references to other texts). The reader in the fully formed hypertext network should be able to choose to read in two temporal directions-synchronically through the text as provided by the author but also diachronically back through the citations to which scholarly texts refer, and of which any text is necessarily composed-a kind of bibliographical reading. Each of the texts cited by the author can be read in a hypertext environment, including any parts of those cited texts not specifically quoted by the author-so that the reader can enter the cited text, and read on both sides, so to speak, of the quotation. Any citations in the cited text can in turn be followed backward to their original sources, and so forth. ${ }^{28}$ And these are only the explicit citations. The reader will in all likelihood also have the ability to use implicit citations, i.e., to create new networks of references by looking for similar texts that use the same signifiers (words, sounds) in similar sequences or proximities in other files accessible throughout the network. ${ }^{29}$ The reader can indeed approach the entire content of the extended network as a single unit (rather like approaching the entire library as a single, multivolume set). Research on the network thus comes to consist fundamentally of defining and redefining parameters, so that the reader does indeed become a writer, creating new texts through new contexts.

Hypertext's main strength, however, is also its greatest potential drawback: its infinite flexibility could create an environment in which the original expression of the author could become obscured or lost altogether:

Hypertext fragments, disperses, or atomizes text in two related ways. First, by removing the linearity of print, it frees the individual passages from one ordering principle-sequence-and threatens to transform the text into chaos. Second, hypertext destroys the notion of a fixed unitary text. Considering the "entire" text in relation to its component parts produces the first form of fragmentation; considering it in relation to its variant readings and versions produces the second. ${ }^{30}$

This propensity for mutability has already been recognized as a potentially serious impediment to scholarly communication, and one which information services will certainly need to confront. ${ }^{31}$ Nelson himself stipulated that a document in its original form-i.e., defined as finished by the author-should be subject to no further alterations, which are not made or condoned by the author. ${ }^{32}$ But at the level of reading, of course, the reader can do whatever he or she wants 
to the original context-that is the nature of hypertext. At the level of reading, there can be no question that the writer will lose substantial authority and autonomy. Hypertext "infringes upon the power of the writer, removing some of it and granting it to the reader." ${ }^{\prime 33}$ The unity and closure of the text as understood by the writer are no longer inviolable. To be sure, the writer, regardless of format, always merely recommends to the reader that the text be considered in a certain form, that it be read in a certain sequence, that it be related to certain parts of certain other texts. The reader is obviously always in the primary control of the reading-but the availability of hypertext and the network, it must be admitted, increases that control dramatically.

\section{FREEDOM AND AUTHORITY}

This diminution of authorial control is only one manifestation of a far more fundamental quality of hypertext and networking - and more generally of information exchange in the online era: the potential forfeiture of origin. We encounter this quality now probably most clearly in the reduction of the significance of location: where a particular segment of information is located is a far less important attribute of that information in a networked environment-not because location no longer exists (the signals that "carry" information are always material and must therefore always reside someplace), but rather because those material signals can now be transported at such speeds that the effect of that transportation on access time becomes imperceptible to the user. All locations become relatively equivalent on the network: they lose their difference, and therefore their significance.

We have noted above that it is people (not computers) who communicate by means of networks; although this, too, is an oversimplification-in the sense that no one ever communicates directly with another person, but rather always with a text of some kind produced by another person. While print certainly tends to level or standardize such communication, the elimination of the perceived differences between one text and another, and thus the obfuscation of origins, becomes even more prevalent in a networked environment. All texts are manifested in the same form on the individual's computer screen. The text with which the reader interacts is something always already written (or copied) by someone on the network. Regardless of whether that someone wrote that text a few minutes or a few seconds before in response to a query by the reader on e-mail, or whether the original writer produced that text years or centuries or millennia ago under totally unknown circumstances-the reader is still engaged in a dialogue not with that person, but rather with the graphic, material signs. The network by virtue of its endemic neutrality encourages the reader to view all texts as current and all authors as contemporaries.

\section{To change the sequence is, again, to change the meaning - so that hypertext provides the reader with the power and authority to affect the meaning of the text.}

Jay David Bolter has examined these issues in some detail in his recent book Writing Space. He concludes that hierarchy in writing is a convention of the print culture, and that the advent of the fully developed hypertext network will free the reader from that hierarchy. ${ }^{34}$ The hypertext network will also liberate the reader from the tyranny of the author, bringing about a welcome "end of authority." 35 This will lead to a "new dialogue" between reader and writer, "which replaces the monologue [of the author] that is the conventional printed essay or monograph." ${ }^{136}$ This tyranny of the author has throughout the print era been most evident, according to Bolter, in the literary canon, which will be replaced in the online age by the "rich texture of allusions and references" of the network. ${ }^{37}$ Sequence becomes the responsibility of the reader: since works in hypertext "do not have a single linear 
order, corresponding to the pages of a book or the columns of the papyrus roll, ... there is no order to violate." ${ }^{\prime 38}$

Bolter clearly misinterprets some of the fundamental textual and epistemological requirements of communication and scholarship. Some structure, some hierarchy, must be preestablished, some works (canon) and terminology (indexes) must be privileged if communication is to take place. The alternative is babel. It is not that the user should be denied flexibility-quite the contrary; but such flexibility must be voluntary. Indeed, flexibility is only possible if there is a structure against which some variation is possible and permitted. The "new dialogue" for which Bolter hankers would itself result in a tyranny-one exercised entirely by the reader. But that is certainly no dialogue. A dialogue rather entails some balanced authority for both parties; the author's recommendations on sequence and structure must be provided and consciously observed (or rejected), therefore, if true dialogue is to take place.

\section{This diminution of authorial control is only one manifestation of a far more fundamental quality of hypertext and networking - and more generally of information exchange in the online era: the potential forfeiture of origin.}

We glimpse perhaps the root of Bolter's misconceptions in his challenge to the infinity of reference:

Semiotics regards representation as a process without end. ... The interpretant, the definition of the sign, may in turn be treated as a sign requiring definition. The process continues in theory as long as we like, because each new interpretant allows for a further interpretation. In fact any practical system is limited. In the dictionary each word is defined in terms of other words that are themselves entries to be consulted, but no dictionary is infinite. If we had the patience, we could ex- amine all the words in the network of definitions contained in the dictionary. By starting often enough at different entries, we could ultimately exhaust the dictionary's writing space. ${ }^{39}$

What Bolter fails to recognize or accept is that all of the terms in the dictionary refer to each other-and to nothing else. Language is a network of self-references. Because each term is only understandable through its relationship to other terms, the signs of which the language is composed are in a state of continuous and ultimately circular reference. That is why referentiality is theoretically infinite. That is why one can never "exhaust" the dictionary's "writing space." That is why it is possible to claim that there is no beginning and no end to the referentiality of language, and that nothing exists outside of the text. And that is, above all, why some structure needs to be imposed upon the text by some acknowledged authority. Some words, some sentences, some documents need to be specially privileged, to influence the order in which texts are encountered and experienced. This need not mean, of course, that there is some kind of natural or endemic value to one text rather than another-as the concept of the canon might indeed imply. The order imposed on the literature is always artificial, in the sense that it reflects relative decisions made by individuals in authority. It is precisely because there are theoretically no natural origins, no beginning and end to language, that we must impose that kind of order-origins, sequence-for purposes of understanding.

We must assume, therefore, that selection in some form will continue to be a primary activity either undertaken or facilitated by information services. Selection in the online era will presumably consist of someone attaching (i.e., linking) something to the text which the reader can use to decide not only whether to retrieve and read that text but also when to retrieve it (i.e., in the reading sequence). Online selection as an information service is, in other words, an act of appending to the text some evaluation of it, and this literally "added value" is the indispensable service that 
will make possible networked scholarly communication.

At the same time, however, we must admit that Bolter and others are fully correct in their realization that networking and such computer applications as hypertext "democratize" information, and permit unprecedented flexibility in text production and manipulation. The "history of information technology from writing to hypertext reveals an increasing democratization or dissemination of power. ${ }^{\prime \prime 0}$ That may be in nuce the conundrum, the core challenge, of information services in the early online era. Control, to be sure, must be provided, selection must take place, order of some kind must be imposed, if access time is to be reduced and overload circumvented for the purposes of scholarship and education-but paradoxically a primary responsibility of academic information services must be to leave the reader at the same time the freedom to ignore such control, and indeed perhaps under some circumstances even to encourage him or her to do so.

\section{FORMAL CONSIDERATIONS}

\section{The Literature}

Will formal publication survive the online age? It need not necessarily. All scholarly communication could conceivably take place through the kind of informal interchanges we now see on the network discussion lists. The homogeneity or neutrality of the network described above reduces also the difference between formal publication and informal communication-but, in the interests of control and sequence, some kind of distinction does need to be made in the online environment between writings that the author alone decides should be made public, and writings that experts in the field (editors) endorse and recommend to other experts to read. Special databases or segments of general databases will therefore need to contain subject or topical files that include publications, i.e., writings that authors declare finished, and that duly authorized peer review boards declare significant. Anyone working in the field will then normally consult these publications first, before beginning to search the network for other information of relevance. ${ }^{41}$ In this way, the core of the subject can be defined, and progress in the discipline can proceed.

\section{Selection in the online era will presumably consist of someone attaching (i.e., linking) something to the text which the reader can use to decide not only whether to retrieve and read that text but also when to retrieve it (i.e., in the reading sequence).}

The clear risk of such a procedure, of course, is that it could lead to an extreme centralization of control over formal publication. If the only categories we have available are (informal) discussion and (formal) publication, and if there are only subject files and no individual journals, and if there are only a few "core" subject files for each discipline, then the editors responsible for deciding what deserves the status of a publication in such subject files could exercise virtually dictatorial control over the development of their respective disciplines. This problem is circumvented somewhat in the print environment through the availability of noncore journals. If there is no equivalent of such a multiplicity of journals in the networked environment, then there may be no opportunity to publish new or unpopular ideas (i.e., outside of "normal science"). It is for this reason that some other categories of scholarly communication will need to be established beyond publication and discussion. Some form of quasi- or individual publication needs to evolve, in which the author alone could vouch for the completeness, quality, and consistency of the publication, and which the reader could then consult on that basis after (presumably) first consulting core or refereed publications..$^{42}$ There is nothing at all wrong with vanity publishingeither in paper or online-provided that it is clearly identified as such. Hypertext will in any case ensure that any "peripheral" publications of this type that are of 
real significance will be linked to future core publications through references.

If the online discussion (as opposed to formal publication -or quasi-publication) is a legitimate part of the network (as it already is), information service operations will need to decide soon whether such discussions should be archived in the same way that we will need to archive and safeguard publications. The archiving of online discussions is a temptation at the present time in the partially developed network, and it is one we need, in my opinion, generally to resist. To feel obliged to retain every human utterance in graphic form makes little sense in the print environment, and none at all in fully networked circumstances. In all probability, we will need to look at the question of storing network discussions in a manner similar to the way we now approach the retention of manuscripts in the paper environment. It is ultimately a preservation question best left in the hands not of librarians but of archivists. Only a small subset of the manuscripts produced are now retained, and similar decisions based on similar criteria will need to be made for networked discussions. As is the case now of manuscripts in the paper environment, most discussions will presumably be preserved by individuals rather than institutions.

\section{The Document}

Monographs and Periodicals. The most basic formal distinction in printed scholarly communication, at least from the standpoint of libraries, is that between monographs (i.e., single books on specific subjects) and periodical articles. The scholarly monograph permits a fully developed statement on a well focused subject, approached usually from a multiplicity of perspectives or examined in a broad context. The monograph is, as its name implies, unitary and separate. The advantage of such closure is that the monograph can define its own terms and create its own internal, self-referring context-a kind of network in print. ${ }^{43}$ The reader must invest some time in the monograph, and while its boundaries are predetermined by the author, the reader always has the option of varying the sequence in which he or she reads the composite parts of the monograph, or of reading it only selectively; most scholarly treatises are doubtless seldom read cover to cover by scholars, but are rather read in. There are also well-known drawbacks to the monograph, however-one being that, aside from some knowledge of the publisher, the reader seldom has adequate advance information about either the quality of the monograph's scholarship or the precise nature of its content. The scholar must first locate-find out about the existence of-the monograph, a task which enumerative bibliography, cataloging, and book reviewing have been able to assist only to a limited extent; and he or she must then invest time reading "into" the monograph to gauge its quality and utility. Information services, with their primary objective being the reduction of access time, have likewise in the paper environment seldom succeeded effectively in reducing the time needed by readers to digest, assess, and make use of monographic information.

Periodical articles, on the other hand, overcome to a certain extent some of the monograph's drawbacks. The value of periodicals for scholarly communication lies not so much in their periodicity, as in the concentration of their content and the predictability of their subject matter. Periodicals reduce the difficulty of location by establishing narrow boundaries for their subjects, so that much of the key knowledge of some disciplines is in effect defined by its inclusion in a relatively manageable set of core periodicals. ${ }^{44}$ The articles published in these core periodicals, in other words, define or represent the current substance of the discipline; developments or ideas not expressed or referred to in the core journals are de facto of less importance-in the sense that the scholar will normally approach information published elsewhere only after he or she first absorbs the information in the core journals. ${ }^{45} \mathrm{~A}$ subject that relies primarily on journal literature is not only more current, therefore, but also arguably under better control than a subject 
dependent mainly upon monographs, in the sense that the periodical-based literature has a more self-defined hierarchy of publication. ${ }^{46}$ The periodical article also has the significant but seldom stated advantage that its absorption by the reader involves a considerably smaller investment of time. While the monograph tries to provide a (partially) closed intertextual network, the periodical leaves the reader more of the responsibility and authority for placing the information in a wider context.

Concentric Stratification. In a fully networked environment, formal scholarly publication can no longer be characterized by the dichotomy of monographs and periodical articles. That distinction makes no sense, if for no other reason than that the economics of online publication no longer requires periodicity: any article or monograph can be published as soon as it has been accepted and edited. Nevertheless, a fundamental objective of information services must be to ensure that the special advantages or capacities of both the monograph and the periodical article in the paper environment are somehow built into the online scholarly communication process. We need, therefore, a formal method of writing that is appropriate to the networkone that will exploit the special capacities of online publication, but that will at the same time retain the values (and avoid the drawbacks) of periodical articles and monographs. Any such method adopted must promote the reduction of access time and contribute to the counteraction of overload-and it should above all enhance communication, in the sense that it should improve participation by both the writer and the reader.

One such method may be for scholarly publications to be presented not in the traditional linear sequence, but rather as a set of linked or self-citing levels or strata. Let us give such a format the contradictory label of concentric stratification in order to emphasize simultaneously the concepts of separation and coincidence. Such a document structure might consist of a top level that would contain some kind of extended abstract; this level or stratum would then be connected to the next level, and so on. Each succeeding level would include the information contained in the previous level, but would provide in addition greater degrees of substance and detail. Scholarly communications that require an extended context, and would therefore deserve a monograph in the paper environment, would in the online environment merely include more levels than would a communication that would in a print environment have been published as a journal article. The top level should contain for indexing and access purposes all terms in the work considered by the author to be critical. There should be some standardization of levels, such that the reader would be able to decide which level to access first, depending on his or her previous knowledge of the subject and on the extent of the information required. Such a document structure would also restore to the author some of the authority and control that will necessarily be forfeited in a hypertext and networked environment, since it would permit the author through such a hierarchical structure to privilege - to assign different values or significance to-different parts of the text.

\section{If the reader is going to read in three directions, then the writer is, of course, going to have to learn to write in three directions-a very different notion of writing from that done in the linear print environment.}

Three-Dimensional Textuality. If formal scholarly publication on the network does indeed shift from a linear form to some kind of hierarchical structure, then reading on the network will be something that is done, so to speak, in three dimensions: first, one can read horizontally or linearly within any level of a given publication ; second, one can read vertically or hierarchically through the levels of any particular publication; and, third, one can read referentially back through the constituent citations 
(be these explicit or implicit) into other texts on the network. ${ }^{47}$

This has, needless to say, some important implications not only for scholarly communication but also for instruction. Students could be given one group of texts or a single text that could conceivably consist of a single key paragraph; from that one text, the student could then construct (reconstruct?) the entire subject by moving linearly, hierarchically, and referentially-rather like growing a complete organism from a single cell. Needless to say, no two students would end up with the same "subject," or rather the same composite text; the responsibility of the instructor would then become to guide the students through the intertextual connections, making certain that the standard or canonical connections are not overlooked but also providing each student with the capacity to build his or her own connections beyond the canonical.

If the reader is going to read in three directions, then the writer is, of course, going to have to learn to write in three directions-a very different notion of writing from that done in the linear print environment. At the very least, the writer will need to create the work hierarchically in linked levels. One assumes that in a paper environment, for example, most authors start with an outline, and then write each section more or less linearly, i.e., seriatim. Writing by using some system like concentric stratification would presumably also begin with some kind of outline, but then the outline of the whole work might be expanded in stages-with each stage functioning eventually as a separate text-stratum. ${ }^{48}$

Writing will also need to include connections to explicit citations. The author should be prepared, moreover, not simply to cite another publication but possibly also to do something to it (i.e., to some copy of it)-to tag it or annotate it in such a way that the reader is able to infer the author's evaluation or application of the cited work. In this way, the author can guide the reader through the cited work, but the reader will still be able to make alternative sequencing decisions. If the author is referring to statistical data rather than to a narrative text, the software needed for that data and the tagging of particular data elements would also be expected. In any case, interaction with the textual history of the subject should become a much more integral aspect of both writing and reading in a fully networked environment.

\section{INFORMATION SERVICES}

Certainly one of the most basic changes for which libraries as information service operations will need to prepare will be the blurring of the distinction between the reader and the writer. Libraries, at least in North America, have developed an aggressive (and admittedly somewhat self-righteous) philosophy based primarily on assistance to-and protection of the rights of - the reader. Libraries have seldom catered to the full needs of the writer (even though most of the readers in academic libraries are usually gathering information in order to write something). In a networked hypertext environment, the writer must be accepted as a client deserving of a level of service at least equal to that of the reader-if for no other reason than that it will become increasingly difficult to separate the activity of reading from that of writing, since both will consist mainly of some manipulation of text on the network. "In a full-fledged hypertext the distinction [between writing and reading] can disappear altogether." ${ }^{\prime 49}$ We must in any event expect the information environment in the online era to be such that, while the library will obviously continue to assist the user in locating information, the main information retrieval service provided by the library may well be indirect-through assistance to those who input or publish information. A central function of information services in the online era, in other words, will be to ensure that information is made available by its originators in such a form and according to such standards that it will be most rapidly accessible and useful to those who need it. 


\section{Publishing}

It is very unlikely - and is would certainly be very undesirable-for the commercial publishing industry to continue to play the same dominant role in scholarly publication in the online environment that it has in the paper environment: that would be economically unacceptable and technically unnecessary. There will certainly be important and profitable opportunities for commercial publishers in the online environment, but the routine publication of scholarly notification sources should not be one of these. ${ }^{50}$ Since the majority of the authors, readers, and editors of scholarly publications are members of academic faculties, it will make very little sense to continue to "contract out" to commercial publishers the responsibility for distributing the written scholarly products of the faculty. The academy, as Richard Dougherty, Ann Okerson, and others have strongly advocated, must assume that responsibility. ${ }^{51}$

It should be the function of academic information services to ensure that national-or preferably internationalpeer review structures are in place. These editorial boards will then continue to do what they do in the paper environment: they will add value to individual articles by endorsing them for publication. The network of "core" servers for each subject area mentioned above needs to be established as soon as possible, so that such publications can then be easily available to all students and scholars. Access to the network for academic users should be free, in the same way that access to the library is free; the cost of its maintenance, in other words, should continue to be borne-as it is today-by the institutions. An infrastructure for individual or vanity publications must also be in place. Each institution will need to establish policies on archiving-especially for such individual publishing and for network discussion list input. It is also highly advisable that institutions retain copyright control for all or most publications by their faculty. In the interest of scholarly information exchange-and because scholarly authors traditionally and correctly receive rewards for publication indirectly in the form of peer recognition and promotion rather than direct remuneration-all scholarly information published by institutions should be free for any person or institution to copy for any noncommercial purpose. ${ }^{52}$

\section{Indexing}

Providing effective access in a networked environment must become increasingly the responsibility of the writer, with the assistance of local information services. The indexing of the text-or whatever we call the additions to the text that will allow the user to locate, understand, and evaluate it-must become in a networked environment an integral part of the writing of the text. Assisting the author with the indexing of his or her writing, so that such indexing (and this may well include specialized software) becomes part of the publication, should become a responsibility that information services undertake at the time the publication is being produced, rather than something libraries or commercial indexers do, as is now the case, subsequent to publication. This professional activity of assisting the writer to produce his or her indexing within the network context, so that readers needing it can find it, will presumably be fundamentally the same activity or service, approached from the opposite direction, requiring the same bibliographical knowledge and skills, as assisting the reader to locate information on the network.

\section{Document Structure}

The replacement of linear reading and writing by a hierarchical structure of some kind (e.g., concentric stratification) will be justified only if that new structure is standardized so that information access is improved. The practicability of the whole enterprise will certainly depend upon prearranged, universally accepted conventions. In the kind of hierarchical structure suggested above, for example, there would need to be some set of abstract guidelines applicable to writing on any topic that would 
define the characteristics of information to be written or located at each level-or more exactly, that would standardize the relationship of the strata or levels to each other. Only in this way would the user be able to exploit the conventions of the structure, in order to arrive at the information needed in the shortest possible time. Defining that structure for all formal scholarly writing, obtaining international agreement on its implementation, assisting authors in their writing so that they make effective use of the structure, and assisting readers in locating the information they need in the shortest time by exploiting that structure-all of these functions should become routine responsibilities of information services in an online environment.

\section{CONCLUSIONS}

Librarians are admittedly control freaks. We yearn to regulate all information exchange, and we have a morbid fear of losing anything. We traditionally interpose ourselves between the user and the information. And now, just when it appears that technology will finally liberate the user from the tyranny of mediation, the library, in its new guise as information service provider, appears poised to insert itself once again between the information seeker and the information sought. There will be some objection to this role, and some rejection of this service-but if information professionals recognize that the imposition of some order and structure on networked information is an essential prerequisite for effective scholarly communication and higher education in an online environment, then plans should be made, regardless of the opposition, to provide that service and to demonstrate how it adds significant value to the functional network. This effort should be made, moreover, even if-or especially if-it is not in the best administrative interest of libraries to do so. If the kinds of information services discussed above are successfully implemented, then not only will the traditional operational divisions within the library (e.g., selection, cataloging, reference) dissolve and be re- constituted in other forms but also the currently clear administrative divisions between the library, computer center, university press, and campus bookstore will become increasingly obscure-so that the need to effect some kind of amalgamation of all campus information services may eventually become irresistible.

It is very unlikely-and it would certainly be very undesirable-for the commercial publishing industry to continue to play the same dominant role in scholarly publication in the online environment that it has in the paper environment: that would be economically unacceptable and technically unnecessary.

Neither networks nor hypertext will separately bring about a true revolution-but in combination they are indeed very likely to engender a radical transformation in scholarly information exchange. Together they provide not simply a new and improved version of what has been done before in paper form, but rather represent fundamental revisions in the very modality of communication; they may even affect and alter some of our basic assumptions about the nature of information itself. The ability especially to augment a text's content through implicit and explicit citation has the most far-reaching implications, which users of networks and hypertext must learn to appreciate. If there is one lesson we have learned, one conclusion we must draw, from the experience of such critical methods as deconstruction, it is surely this: if we push intertextuality far enough, if we take it upon ourselves to explore a large enough range of the previous uses of the signs of which a text is composed, if we broaden the context enough, then the reference of those signs and the meaning of that text will diminish and dissolve. Meaning is fragile, and the capacity of the network for a theoretically infinite combining and recombining of texts can jeopardize meaning in a fundamental sense. The 
hypertext-enhanced network is indeed a machine of enormous power and promise, but like all powerful machines, it will need to be skillfully designed and responsibly operated by those who understand and respect its potential.

\section{REFERENCES AND NOTES}

1. According to testimony of Douglas E. Van Houweling in the House Committee on Science, Space, and Technology, Subcommittee on Science, Management of NSFNet, 102d Cong., 2d sess., Mar. 12, 1992, 38 (also currently available by FTP from nis.nsf.net/internet/legislative.actions/ hearing, Mar. 12 1992), between July 1988 and March 1992, "traffic on the [NSF] backbone has grown almost 7,000 percent, an average of 11 percent compounded every month, and new applications and uses are constantly emerging."

2. Congressional Record 137:174 (Nov. 22, 1992), S17730. The NSF Backbone is just completing its transition from T1 (1.5 megabits per second) to T3 ( 45 megabits per second). See the Link Letter 5, no.1 (Mar./Apr. 1992), 1, 8-9 (also currently available by FTP from nic.merit.edu/newsletters/linkletter). A megabit is one million bits; a gigabit is one billion bits. By contrast, the original ARPANET put into operation in 1969 was run over wideband telephone linés that permitted transmissions of 50 kilobits (i.e., 50,000 bits) per second (Dennis G. Perry, Steven H. Blumenthal, and Robert M. Hinden, "The ARPANET and the DARPA Internet," Library HiTech 6:2 [1988], 51).

3. This bill, sponsored by Senator Albert Gore, is currently (Summer 1992) pending in the Senate as S-2937. For the text of the bill, see Congressional Record 138, no.97 (July 1, 1992), S9539-41. A copy of the press release describing the bill is currently available by FTP from nis.nsf.net/internet/legislativeactions/iita.1992/ gorebill.1992.txt.

4. For good summaries of these issues, especially as they relate to the development of the NREN, see Clifford A. Lynch, "The Development of Electronic Publishing and Digital Library Collections on the NREN," Electronic Networking 1, no.2 (Winter 1991), 6-22; Edwin Brownrigg, "Developing the Information Superhighway: Issues for Libraries" in Carol A. Parkhurst, ed., Library Perspectives on NREN: The National Research and Education Network (Chicago: Library and Information Technology Assn., 1990), 55-63; and Charles R. McClure, Ann P. Bishop, Philip Doty, and Howard Rosenbaum The National Research and Education Network (NREN): Research and Policy Perspectives (Norwood, N.J.: Ablex, 1991), especially Chapters 3 and 9.

5. We must be especially careful in the academic environment to avoid assuming that most uses of the Internet are for scholarly purposes. See the testimony of Mitchell Kapor in House Committee on Science ..., Management of NSFNet, 78 : [nearly] "60 percent of all registered computing sites in the Internet are commercial organizations. Within two years the number is expected to grow to nearly 90 percent."

6. Two good summaries of the copyright issues are Paul Hilts, "Through the Electronic Copyright Maze," Publishers Weekly 239, no.26 (June 8, 1992): 35-37; and Robert L. Oakley, "Copyright Issues for the Creators and Users of Information in the Electronic Environment," Electronic Networking 1, no.1 (Fall 1991), 23-30.

7. See Gordon Cook, "A National Network That Isn't," Computerworld 26, no.10 (Mar. 9, 1992): 91-95.

8. The interviews undertaken by the McClure team showed a clear aversion by scientists to publishing in online journals: this is because "the reward structure of science is based on formal publication history and ... electronic publication does not enhance one's status or image; in fact, it may very well harm them." (McClure, The National Research and Education Network, 103.)

9. One major technical issue still to be resolved, for example, is protocol interoperability. On this see Lorcan Dempsey, Libraries, Networks and OSI: A Review, with a Report on North American Developments (Bath: U.K. Office for Library Networking, 1991), especially Chapter 2; see also the review of this report by Clifford Lynch in The Public-Access Computer Systems Review 2, no.1 (1991): 171-76.

10. Richard N. Katz, "Academic Information Management at the Crossroads: Time Again to Review the Economics," Serials Review 18, nos.1/2 (1992): 43. 
11. A sign, according to Umberto Eco in his A Theory of Semiotics (Bloomington, Ind:: Indiana Univ. Pr., 1976), 16, is "everything that, on the grounds of a previously established social convention, can be taken as standing for something else."

12. See my "The Conditions of Collection Development" in Charles B. Osburn and Ross Atkinson, eds., Collection Management: A New Treatise (Greenwich, Conn.: JAI Pr., 1991), $1: 37-42$.

13. John S. Quarterman, The Matrix: Computer Networks and Conferencing Systems Worldwide (Bedford, Mass.: Digital, 1990), 6.

14. Eco, Theory of Semiotics, 20.

15. A good example is the relationship of the NREN to the Internet and NSFNet. Will the Internet "Evolve into NREN," (Vinton G. Cerf, "Introducing the Internet" in Parkhurst, Library Perspectives on NREN, 20, figure 6); or will "the current NSFNET ... become the Interim NREN" (Michael M. Roberts, "Positioning the National Research and Education Network," EDUCOM Review 25 [Fall 1990]: 12); or is the NREN already well in place, with NSFNET "currently" serving "as the primary cross-continental backbone for the NREN, which now links over one thousand university and college campuses ..." (Stephen Gould, "Building the National Research and Education Network," CRS Issue Brief [IB90126] [Washington, D.C.: Library of Congress, "Updated Dec. 18, 1991], 1)? It is perhaps not so much the network itself as the literature describing it that is becoming too complicated to understand.

16. These three views of the network are perhaps roughly equivalent to Robert Kahn's three infrastructure components: the network, the databases, and the infrastructure intelligence-except that he quite rightly includes protocols as part of the network rather than as part of the infrastructure intelligence-in his "National Information Infrastructure Components," Serials Review 18, nos.1/2 (1992): 85-87.

17. For a readable introduction to hypertext, see Carl Franklin, "Hypertext Defined and Applied,"Online 13, no.3 (May 1989): 37-49. See also Michael Knee and Steven D. Atkinson, Hypertext/Hypermedia: An Annotated Bibliography (Westport, Conn.: Greenwood, 1990).

18. Nicole Yankelovich, Bernard J. Haan, Norman K. Meyrowitz, and Steven M. Drucker, "Intermedia: The Concept and the Construction of a Seamless Information Environment," Computer 21, no.1 (Jan. 1988): 81. Jay David Bolter, in his Writing Space: The Computer, Hypertext, and the History of Writing (Hillsdale, N.J.: Erlbaum, 1991), 27, notes that "the principle of hypertext has been implicit in computer programming" for some time. "Hypertext is the interactive interconnection of a set of symbolic elements, and many kinds of computer programs (databases, simulation programs, even programs for artificial intelligence) are special cases of that principle."

19. T. H. Nelson, "A File Structure for the Complex, the Changing and the Indeterminate, Association for Computing Machinery: Proceedings of the 20th National Conference (New York: Assn. for Computing Machinery, 1965), 96 and 98.

20. Ted Nelson, Literary Machines: The Report on, and of, Project Xanadu concerning Word Processing, Electronic Publishing, Hypertext, Thinkertoys, Tomorrow's Intellectual Revolution, and Certain Other Topics including Knowledge, Education and Freedom, 3d ed. (Swarthmore, $\mathrm{Pa}$.: the author, 1981), $1 / 22$ and $2 / 21$. This is a difficult work to cite, in that it has been updated and reissued several times. The copy I used is owned by the Harvard University Law Library.

21. For example, Philip Seyer, in his Understanding Hypertext: Concepts and Applications (Blue Ridge Summit, Pa.: Windcrest, 1991), 1, describes hypertext as "nonlinear, or nonsequential, text. That is, the text is organized so you can easily jump around from topic to topic. You do not need to read the text in fixed sequence."

22. Julia Kristeva, "Word, Dialogue and Novel," trans. Alice Jardine, Thomas Gora, and Leon S. Roudiez, in The Kristeva Reader, ed. Toril Moi (New York: Columbia Univ. Pr., 1986), 37.

23. Several good surveys of intertextuality are available. See, for example, Marc Angenot, "L'Intertextualité: enquête sur l'émergence et la diffusion d'un champ notionnel," Revue des sciences humaines 60, no.189 (Jan/Mar 1983): 121-35; Ottmar Ette, "Intertextualität: Ein Forschungsbericht mit literatursoziologischen Anmerkungen," Romanistische Zeitschrift für Literaturgeschichte 9, nos.3/4 (1985): 497-522; Thais E. Morgan, "Is There an 
Intertext in This Text?: Literary and Interdisciplinary Approaches to Intertextuality," American Journal of Semiotics 3, no.4 (1985): 1-40.

24. Julia Kristeva, "Revolution in Poetic Language," trans. Margaret Waller, in The Kristeva Reader, 111.

25. Laurent Jenny, "La Stratégie de la forme," Poétique 27(1976): 261.

26. Roland Barthes, Theory of the Text," trans. Ian McLeod, in Untying the Text: A PostStructuralist Reader, ed. Robert Young (Boston: Routledge \& Paul, 1981), 32.

27. Probably the most effective analysis of the relationship between hypertext and poststructuralist literary theory will be found in George P. Landow, Hypertext: The Convergence of Contemporary Critical Theory and Technology (Baltimore: Johns Hopkins Univ. Pr., 1992).

28. Bolter, Writing Space, 15.

29. This would presumably be one use of the so-called knowbot. See Robert E. Kahn and Vinton G. Cerf, The Digital Library Project: An Open Architecture for a Digital Library System and $a$ Plan for its Development, vol.1: The World of Knowbots (draft), (n.p.: Corporation for National Research Initiatives, 1988). See also Bennett Daviss, "Computer Watch," Discover 12, no.4 (April 1991): 21-22.

30. Landow, Hypertext, 54.

31. See Gordon B. Neavill, "Electronic Publishing, Libraries, and the Survival of Information," Library Resources \& Technical Services 28, no.1(Jan./Mar. 1984): 76-89; and Peter S. Graham, "Electronic Information and Research Library Technical Services," College \& Research Libraries 51, no.3 (May 1990): 241-50.

32. "Ordinarily a document consits [sic] of its contents (including history and alternatives) and its out-links. These out-links are under control of its owner, whereas its in-links are not." (Nelson, Literary Machines, 2/27.) An "out-link" is presumably a link from the original, owned document to another document, while "in-links" are presumably the links from other (not owned) documents to the owned document. See also the chapter in Literary Machines on electronic publishing (2/34-2/45).

33. Landow, Hypertext, 71.

34. Bolter, Writing Space, 22-25 and 112-14.

35. Ibid, 153.

36. Ibid, 117.

37. Ibid, 153.

38. Ibid, 119 .

39. Ibid, 203.

40. Landow, Hypertext, 174.

41. This is a combination of the Acquisition-on-Demand Model and the Discipline-Specific Literature Base Model as defined in Czeslaw Jan Grycz, "Economic Models for Networked Information," Serials Review 18, nos.1/2 (1992): 12-13. See also in the same issue of Serials Review, 78-81, the article by Charles W. Bailey, Jr., on "The Coalition for Networked Information's Acquisition-on-Demand Model: An Exploration and Critique."

42. See Stevan Harnad's very reasonable idea of a hierarchy of discussion groups, out of which would emerge a hierarchy of online publications, in his "Scholarly Skywriting and the Prepublication Continuum of Scientific Inquiry," Psychological Science 1, no.6 (Nov 1990): 343-44.

43. I hasten to note that no publication is, of course, ever fully self-contained, since it is connected with other publications specifically through references and quotations, and more broadly by virtue of intertextuality.

44. See Charles B. Osburn, "The Place of the Journal in the Scholarly Communications System," Library Resources \& Teclinical Services 28, no.4 (Oct./Dec. 1984): 322.

45. It is not, again, that information $\mathrm{A}$ in a core journal is somehow endemically superior to information B in a noncore journal, but rather only that information $\mathrm{A}$ in the core journal will normally be read first, and will therefore normally condition the understanding of information B.

46. It is in fact this hierarchical quality or position which is actually being marketed by commercial science publishers: that is what the highly reputable or core journal provides to the material it publishes. Whether that value added is worth the prices some commercial publishers now charge is, of course, another question. 
47. Reading would probably also take place at the same level across different but related publications; although this might also be viewed as a further form of referential reading, since it might be based on "implicit" references or links.

48. It would probably be possible for some kind of "outliner" software to be produced that would assist with this work, although care would obviously need to be taken to leave the evaluative decisions entailed in such outlining fully in the hands of the author. For a discussion of the concept of the outline as it relates to word processing, see Michael Heim, Electric Language: A Philosophical Study of Word Processing (New Haven: Yale Univ. Pr., 1987), 139-45; see also his discussion (243-46) of Gabriele Lusser Rico's concept of "clustering."

49. Bolter, Writing Space, 216.

50. By "notification sources" I mean those publications that scholars write in order to keep each other informed of the results of their research and scholarship. Most scholarly publications today-both monographs and journal articles-are notification sources. See my "Old Forms, New Forms: The Challenge of Collection Development," College \& Research Libraries 50, no.5(Sept. 1989): 514-15.

51. See, for example, Richard M. Dougherty, "A 'Factory' for Scholarly Journals," Chronicle of Higher Education 38, no.41(June 17, 1992), B1 and B3; and Ann Okerson, "Back to Academia? The Case for American Universities to Publish Their Own Research," Logos 2, no.2 (1991): 106-12.

52. This is roughly the copyright policy of The Public-Access Computer Systems Review. Robert L. Oakley ("Copyright Issues," 25) has noted, however, that this could create some legal difficulties "because of the potential for disagreements over the line between commercial and noncommercial use." 


\section{TECHNOLOGY FOR THE 90's AND FOR THE LIBRARIES OF TOMORROW}

\section{BLACKWELL'S PROUDLY INTRODUCES...}

\section{FOR COLLECTION DEVELOPMENT}

BLACKWELLS

$\mathrm{B}$ ackwell's New Titles Online database now includes Tables of Contents and Descriptive Summaries for new and forth-coming scholarly monographs.

- Browse the contents pages before placing the order

- View the publisher's title description

- Order the title electronically

- Insure a title is included on approval

- Access through the INTERNET

\section{FOR PUBLIC ACCESS CATALOGS} BLACKWELL' 1505

$\mathrm{B}$ ackwell's MARC With Books ${ }^{\circledast}$ service now offers LCMARC records enriched with Tables of Contents.

- Enhance subject access

- Improved chapter-level author access

- View contents \& summaries in your PAC before searching the shelves

- Increase interlibrary loan efficiency

FIND OUT HOW EASY AND COST EFFECTIVE IT CAN BE TO GET CONTENTS INFORMATION TO BOTH YOUR STAFF AND PATRONS TODAY!

\section{BLACKWELL NORTH AMERICA, INC. \\ TECHNICAL SERVICES DIVISION}

